Dig Dis Sci. 2017 July ; 62(7): 1683-1691. doi:10.1007/s10620-017-4510-5.

\title{
Epidemiology of recurrent acute and chronic pancreatitis: Similarities and differences
}

\author{
Jorge D Machicado, MD and Dhiraj Yadav, MD, MPH \\ Division of Gastroenterology \& Hepatology, University of Pittsburgh Medical Center, Pittsburgh, \\ PA
}

\begin{abstract}
Emerging data in the past few years suggest that acute (AP), recurrent acute (RAP) and chronic pancreatitis $(\mathrm{CP})$ represent a disease continuum. This review discusses the similarities and differences in the epidemiology of RAP and CP. RAP is a high-risk group, comprised of individuals at varying risk of progression. The premise is that RAP is an intermediary stage in the pathogenesis of $\mathrm{CP}$, and a subset of RAP patients during their natural course transition to $\mathrm{CP}$. Although many clinical factors have been identified, accurately predicting the probability of disease course in individual patients remains difficult. Future studies should focus on providing more precise estimates of the risk of disease transition in a cohort of patients, quantification of clinical events during the natural course of disease, and discovery of biomarkers of the different stages of the disease continuum. Availability of clinically-relevant endpoints and linked biomarkers will allow more accurate prediction of the natural course of disease over an intermediate or long term based characteristics of an individual patient. These endpoints will also provide objective measures for use in clinical trials of interventions that aim to alter the natural course of disease.
\end{abstract}

\section{Keywords}

chronic pancreatitis; recurrent acute pancreatitis; epidemiology

\section{Introduction}

Acute (AP) and chronic pancreatitis (CP) were believed to be distinct entities as late as the Marseilles conference in $1984 .{ }^{1}$ In this revised classification, it was commented that progression from AP to CP is extremely uncommon. The Revised Marseilles ${ }^{1}$ and Cambridge $^{2}$ classifications acknowledged that alcoholic CP may present as a clinical episode of AP, and the latter classification further acknowledged that development of $\mathrm{CP}$ is not inevitable in all patients with alcoholic AP. It was also commented that at least $30 \%$ of all CP might be of idiopathic etiology. ${ }^{1}$ These expert recommendations were drawn from observations that the etiology of $\mathrm{CP}$ in the large majority of patients was alcohol, and

Corresponding Author: Dhiraj Yadav MD MPH, Professor of Medicine, Division of Gastroenterology, Hepatology \& Nutrition, University of Pittsburgh School of Medicine, 200 Lothrop Street, M-2, C-Wing, Pittsburgh, PA 15213, Phone: 412-864-7085, Fax: 412-648-9378,yadavd@upmc.edu.

Potential competing interests: No relevant conflicts of interest. 
supported by autopsy studies documenting frequent occurrence of pancreatic fibrosis in heavy alcoholics without clinical history of pancreatitis. ${ }^{3}$

The concept that recurrent attacks of AP lead to CP by healing of the areas of necrosis with fibrotic tissue was proposed initially by Comfort et al in 1946. ${ }^{4}$ Later, Kloppel and Maillet described the necrosis-fibrosis sequence hypothesis, which was confirmed by clinicopathological studies in well-characterized patients with CP. ${ }^{5-8}$ The SAPE (Sentinel Acute Pancreatitis Event) hypothesis built upon the necrosis-fibrosis theory, and suggested $\mathrm{AP}$ as a sentinel event in the pathogenesis of $\mathrm{CP}$, which, in the presence of continuing exposure to risk factors and aberrations in the repair process leads to $\mathrm{CP}^{9}{ }^{9}$ Over the past 2 decades, clinical data accumulated from human studies confirms that AP, recurrent acute pancreatitis (RAP) and CP represent a disease continuum. ${ }^{10,11}$

This review discusses the similarities and differences in the epidemiology of RAP and CP. The premise is that RAP is an intermediary stage in the pathogenesis of CP, and a subset of RAP patients during their natural course transition to CP. Recognition of this continuum has clinical relevance to develop preventive strategies before the irreversible features of endstage $\mathrm{CP}$ are established.

\section{Definitions of RAP and CP}

The term RAP was first used $\sim 70$ years ago. ${ }^{12}$ This broad term refers to the presence of at least two separate documented episodes of pancreatitis with a period of resolution in between, and the absence of definitive changes of CP. The differentiation between RAP and CP is based on morphology and/or histology of the pancreas. A subset of RAP patient may show histological evidence of $\mathrm{CP}$, however, due to the lack of histology in most patients during clinical care, and for the purpose of this review, differentiation between the two is based primarily on evidence of definitive changes of $\mathrm{CP}$ on cross-sectional studies.

RAP was defined by two distinct terms in the first Marseilles symposium in $1963^{13}$ relapsing acute pancreatitis or acute recurrent pancreatitis (ARP) to describe relapsing acute events due to a removable cause of pancreatitis, which does not progress to CP (such as gallstones, medications); and chronic relapsing pancreatitis (CRP) to describe relapsing attacks of AP associated with anatomic and functional derangement where the probability of transition to CP is high. In patients with CRP, recurrent attacks of AP could therefore be considered to be the manifestation of $\mathrm{CP}$ before definitive hallmarks are documented. Conceptually, these definitions are helpful in retrospect to describe the natural course of RAP. However, due to the difficulty to clinically distinguish between these groups, these terms were deleted from the Revised Marseilles and Cambridge classifications, and are not used in clinical practice. ${ }^{1,2}$ Our description of RAP in this review does not differentiate between ARP and CRP. We make specific comments on the relevance of etiology(ies) and situations to the probability of disease progression.

Natural history studies have quantified the risk of progression after a single attack of AP or RAP. ${ }^{10}$ Although this risk is consistently greater in patients with alcohol and genetic etiologies, transition to $\mathrm{CP}$ is not absolute even in these groups. Moreover, a small but 
significant fraction of patients with other etiologies may also transition to CP. As our focus moves from symptomatic management of $\mathrm{CP}$ to considerations for primary and secondary prevention, and with new treatments potentially available for testing in the near future, identifying subsets of patients who are at high-risk of progression, irrespective of etiology, to definite $\mathrm{CP}$ would be important, as they may be candidates for treatments that may alter the natural course of disease. RAP is an example of one such high-risk group, within which there will be subgroups with varying risk of progression based on etiology, genetic mutations, environmental factors, and clinical features. It is also important to recognize that while the majority of $\mathrm{CP}$ patients are preceded by at least one attack of AP, up to a third of patients may have subclinical AP episodes or no history of AP at all. ${ }^{14}$

There is no current consensus definition of CP. Among the many proposed over the years, a consistent requirement has been the documentation of irreversible changes either histologically (i.e. fibrosis, atrophy) or morphologically (i.e. calcifications, ductal abnormalities) with or without other accompanying features (e.g. pain, AP or RAP), organ dysfunction (diabetes, exocrine insufficiency) and impaired quality of life..$^{1,2,13,15-20}$ The limitation of these definitions is their reliance on the end-stage features. While a definition of probable $\mathrm{CP}$ has been suggested in the presence of subtle histologic or morphologic findings, diagnosing $\mathrm{CP}$ at an earlier stage can be challenging. ${ }^{16,21}$ Development of obvious morphological changes, which are surrogate for fibrosis on histology, may take months to years to develop. Moreover, clinical features (e.g. pain, diabetes and exocrine insufficiency) do not always correlate with morphological features of $\mathrm{CP}^{22}$ Thus, waiting for development of advanced features of CP may limit ones' ability to intervene at an earlier stage.

Recognizing these limitations, a new consensus definition was recently proposed by a group of experts from the United States, Germany, India, Italy, and Japan. ${ }^{23}$ They defined CP as a pathologic fibro-inflammatory syndrome of the pancreas in individuals with genetic, environmental and/or other risk factors who develop persistent pathologic responses to parenchymal injury or stress. The key features of this definition are the recognition that endstage disease is a result of progression through earlier stages, which although not required, are often observed clinically during the evolution of CP. The stages of the disease begin with no pancreatic disease, and transition through AP, RAP, early CP, established CP and endstage $\mathrm{CP}$. The last two stages are similar to the definitions mentioned earlier and characterized by irreversible features such as pancreatic atrophy, fibrosis, duct distortion and stricture, calcifications, pancreatic exocrine dysfunction, pancreatic endocrine dysfunction, and dysplasia with or without a pain syndrome.

\section{Incidence and prevalence}

The incidence of first-attack of AP in population studies over the past 2 decades from different countries ranges from 15 to 45 per 100,000 per year. ${ }^{24-29}$ In a systematic review of published studies, the risk of recurrence after the first-attack of AP was noted to be $\sim 20 \%$, and the risk of progression in patients with at least one recurrence (i.e. RAP) to CP to be $\sim 35 \% .{ }^{10}$ Data are also available on the incidence of $\mathrm{CP}$, and in a few studies, on the prevalence of CP during the same time period. The incidence of CP ranges from 4 to 14 per 100,000 per year, and prevalence from 13 to 52 per 100,000 population. ${ }^{30-35}$ 
The exact incidence and prevalence of RAP are unknown. One can use information on the incidence of first-episode AP and the risk of recurrences to generate estimates for the burden of RAP in the general population. The approximate estimates of incidence rates for AP and $\mathrm{CP}$ in the US are 40-50 and 4-5 per 100,000 population per year respectively, and the prevalence of CP is $40-50$ per 100,000 population (total cases $~ 150,000-200,000$, adjusted for underestimation and racial differences). Using this information, the rates of recurrence after first-attack of AP, and possibility of additional attacks of AP in patients with RAP, the approximate incidence of RAP is likely $\sim 8-10$ per 100,000 per year, and its prevalence $\sim 110-140$ per 100,000 population ( $350,000-500,000$ cases).

\section{Demographics}

First-attack of AP typically affects individuals in their sixth decade of life, with either a slight male preponderance or a similar gender distribution. ${ }^{24}$ Patients with RAP are younger, typically in their fourth or fifth decade of life, and more likely to be men. ${ }^{36-39}$ In a large retrospective study describing all AP admissions during a 20-year period in a single Swedish hospital, patients with RAP were 5 years younger and of male predominance when compared with the entire study population. ${ }^{39} \mathrm{CP}$ patients are also predominantly male, and usually diagnosed in the fifth or sixth decades of life. ${ }^{14,30,32,40,41}$

Differences in the age and sex distribution of RAP patients when compared with those with first-attack AP is likely related to a narrower spectrum of etiologies (less gallstones, more alcohol) and a higher risk of recurrence in younger patients (<40 years). ${ }^{11,38,42}$ An earlier age at onset of RAP when compared with CP suggests the possibility of continuum of the disease process. This has been elegantly demonstrated in studies of patients with hereditary and alcoholic etiologies.

Hereditary pancreatitis typically presents in childhood, with variable frequency of RAP attacks until CP progression by the second or third decade of life. ${ }^{43,44}$ The peak incidence for alcoholic CP in women is between 35-44 years and in men between 45-54, whereas peak incidence of alcoholic AP is 10 years earlier. ${ }^{32,45}$ Incidence of idiopathic AP increases with age and plateaus after 65 years of age, while idiopathic $\mathrm{CP}$ has a bimodal age distribution with first peak during the third decade of life (early onset) and a second peak during the sixth to seventh decades of life (late onset). ${ }^{32,45,46}$

Racial differences have been described for AP and CP. When compared with whites, black patients with AP are more likely to be diagnosed with alcoholic etiology, and they have a higher rate for re-hospitalization. ${ }^{42,47}$ In the NAPS2 studies, black CP patients were noted to have 4.3 times greater odds for physician-reported alcohol etiology when compared with white CP patients. ${ }^{14}$ It is likely that these differences will also be reflected for RAP.

\section{Etiology}

Similar to the first-attack of AP, the two most common causes of RAP are heavy alcohol consumption and gallstones. ${ }^{24,36,38}$ The relative contribution of heavy alcohol consumption is likely greater for RAP than gallstones, although this may vary based on the demographic distribution of the group at risk. Overall, the etiologic spectrum of RAP is narrower than AP, 
since many of the modifiable causes are often addressed or eliminated (e.g. gallstones, medications, etc.) after occurrence of the first-attack. Certain etiologies such as pancreas divisum, genetic causes, etc. are over-represented in RAP patients, in part due to performance of a more comprehensive work-up only after the occurrence of a second attack. The etiologic spectrum of CP overlaps with RAP, but is narrower, with alcohol by far being the most common etiology, followed by idiopathic and genetic etiologies. ${ }^{14,31,34,41}$ Table 1 shows a non-exhaustive list of causes of RAP and CP, of which select are discussed below.

The probability of recurrences after an episode of gallstone-related AP is directly related to whether and how long after an attack a cholecystectomy is performed. ${ }^{48,} 49$ Cholecystectomy as soon as feasible after AP virtually eliminates the risk of subsequent attack(s), except for when a stone may have been inadvertently left or develops in the common bile duct. While 2 to $6 \%$ patients are reported to develop CP after a first episode of biliary pancreatitis ${ }^{11,42,50}$, gallstones do not typically result in CP, except for obstructive mechanisms from a stricture in the pancreatic duct caused by necrotizing pancreatitis. It is likely that in many patients with presumed gallstone pancreatitis who transition to $\mathrm{CP}$, AP was idiopathic or related to another unappreciated cause.

Alcohol is the most common cause of RAP and CP. Average amount, duration of drinking and cumulative exposure are the most important determinants of increased risk of pancreatitis related to alcohol. Estimates of risk (odds ratio or hazard ratio) related to heavy consumption ( $\geq 4-5$ drinks/day) are consistent across studies. ${ }^{51,52}$ Cumulative exposure to alcohol was greater among patients with $\mathrm{CP}$ when compared with those who had AP in a study from Japan, and this difference was more apparent in women when compared with men. ${ }^{53}$ Such a comparison has not been performed for RAP, but it is likely that cumulative alcohol exposure is lower in RAP patients when compared with CP. Alcohol increases the susceptibility to pancreatitis by affecting pancreatic physiology at multiple levels, of which the most important one is its ability to sensitizes the pancreas to other insults. ${ }^{54,55}$ One such co-factor is smoking, which can also increase the risk of pancreatitis independently. ${ }^{56,57}$ Genetic susceptibility can explain an increased risk of pancreatitis in some individuals who also drink. Examples of this include over representation of claudin-2 mutation in patients with RAP and CP with alcohol etiology, and of polymorphisms in alcohol metabolizing genes among patients with pancreatitis in Asian populations. ${ }^{58-60}$

Several genetic susceptibility factors can be identified in patients with RAP and CP, especially those with no other identifiable etiologies. Gain-of-function mutations in the cationic trypsinogen gene (PRSSI) cause hereditary pancreatitis, a rare autosomal dominant disorder with early onset of RAP and CP. ${ }^{61}$ In contrast, a substitution of glycine by arginine at codon 191 of the anionic trypsinogen gene (PRSS2) is less frequent in CP patients when compared with controls, suggesting a protective effect. ${ }^{62}$ Heterogeneous mutations of the serine peptidase inhibitor Kazal type 1 (SPINK1) gene are observed in 1-3\% of the general population or in patients with a sentinel episode of AP, but in $11 \%$ of those with RAP, and in up to $42 \%$ of those with idiopathic CP in India. ${ }^{63-65}$ Interestingly, a Chinese study showed that SPINK1 variants are more common in early- than late onset-idiopathic CP (32 vs. $2 \%) .{ }^{66}$ Mutations in the cystic fibrosis transmembrane conductance regulator (CFTR) gene are common among patients with idiopathic $\mathrm{CP}$ - up to $25 \%$ are compound heterozygotes 
with a severe mutation on one and a mild-variable mutation on the second allele. ${ }^{67}$ The risk of clinical pancreatitis in cystic fibrosis patients who are pancreas sufficient is related to the amount of residual CFTR function, and up to 13 and $5 \%$ may have RAP and CP. ${ }^{68}$ More recently, minor $C F T R$ gene mutations that primarily affect bicarbonate transport have also been associated with an increased risk of pancreatitis. ${ }^{69}$ Mutations in other genes (e.g. chymotrypsin $\mathrm{C}$ [CTRC], calcium-sensing receptor [ $C A S R$ ], carboxypeptidase [ $C P A]$ ) also increase susceptibility to pancreatitis, but precise estimates of risk for RAP and CP with these mutations is less clear. ${ }^{70}$

Hypertriglyceridemia (HTG) is a well-established cause of RAP, but not so for CP. HTGrelated pancreatitis typically occurs in individuals with a common genetic abnormality of lipid metabolism and one or more secondary risk factors such as poorly controlled diabetes, heavy alcohol consumption, obesity, offending medication, and/or pregnancy. ${ }^{71}$ Traditionally, a level greater than $1000 \mathrm{mg} / \mathrm{dl}$ is associated with pancreatitis, but recent studies suggest that the risk increases at levels as low as $177 \mathrm{mg} / \mathrm{dL} .{ }^{72}$ Hypercalcemia is a rare cause pancreatitis, and a true association is debated. ${ }^{73}$

The causal relationship between pancreas divisum alone and pancreatitis is controversial. Since pancreas divisum is common in the general population (up to $5-10 \%)^{74}$, additional factor(s) may be needed in these subjects to increase the risk of pancreatitis. One such factor may be $C F T R$ mutations, which were noted to be over represented among patients with RAP and CP when compared with controls and pancreatitis patients with other etiologies. ${ }^{75}$ These data however need to be replicated in other studies. The relationship between sphincter of Oddi dysfunction with RAP and CP is also controversial. Results of the EPISOD trial have empirically shown that addressing sphincter hypertension does not alleviate pain symptoms with presumed or proven sphincter of Oddi dysfunction. ${ }^{76}$ Similarly, elevated sphincter pressures are highly prevalent in patients with idiopathic RAP, raising the possibility that this is likely the result of RAP and CP rather than the cause. ${ }^{77,78}$

Other causes are considered rare. Over 100 drugs can cause AP by different mechanisms, and if not discontinued, can cause recurrent episodes. Medications do not cause CP. ${ }^{79}$ Patients with celiac disease have 2- to 3-fold greater risk of developing pancreatitis (AP or $\mathrm{CP}$ ) when compared with the general population; the highest risk of such diagnosis is within the first year of detection. ${ }^{80}$ In celiac disease, the pancreas is sensitized by altered levels of autoregulatory enteric hormones and papillary inflammation. ${ }^{81}$ Features of RAP or CP have also been demonstrated in patients with autoimmune pancreatitis (AIP), more commonly in patients with type 2 than type 1 AIP. ${ }^{82,83}$

\section{Natural history}

The natural history in RAP patients could take one of the following three clinical scenarios i) some may have none or more attack(s) of AP with preserved exocrine and endocrine function; ii) some may in addition develop varying combination of abdominal pain symptoms, functional derangement but do not progress to develop morphological changes of $\mathrm{CP}$; and, iii) some may have varying combination of AP attack(s), abdominal pain symptoms and functional derangement and develop morphological progression to $\mathrm{CP}$. 
In observational studies of patients after the first-attack of AP, among patients who had at least one recurrence, $36 \%$ subsequently progress to $\mathrm{CP} .{ }^{10}$ The probability of transition from RAP to CP can be highly variable; known predictors include underlying etiology, ongoing alcohol and tobacco use, burden of RAP episodes, and presence of pancreatic necrosis during AP attacks. 7, 11, 42, 50, 84-87 The prevalence and pattern of pain and functional derangement in RAP patients who do not develop morphological changes of $\mathrm{CP}$ is not well studied. While these data provide a good summary of the natural history, a study of RAP patients based on specific etiologies is more illustrative.

Following the first episode of alcoholic pancreatitis, 25 to $50 \%$ progress to RAP. ${ }^{11,42,50,86}$ Of those with RAP, 42 to $80 \%$ may progress to $\mathrm{CP} .{ }^{50,84,86}$ The risk of disease progression is linked to continuation of drinking and smoking habits. ${ }^{11,42,50,86}$ A Japanese study found that in patients who continued to drink at the same level, the risk of subsequent recurrences and progression to $\mathrm{CP}$ was the greatest at $58 \%$ and $41 \%$ respectively, and was the lowest (20\% and 13\%) among those who stopped drinking completely. ${ }^{50}$ Observations in a cohort from Finland found similar results, and in a randomized trial they demonstrated a beneficial effect of abstinence on disease recurrences. ${ }^{88,89}$

Progression from AP to CP is also high in the presence of genetic susceptibility factors. Hereditary pancreatitis related to PRSS1 mutation, though an uncommon cause of RAP and $\mathrm{CP}$, has the greatest risk of transition from AP to CP. Overall, $80 \%$ subjects carrying the mutation have at least one episode of AP, and about half of them progress to $\mathrm{CP}$, usually after one or more attacks of RAP. ${ }^{43,44}$ The risk of AP, RAP and CP in subjects who are heterozygote for $C F T R$ mutations, homozygote for milder mutations in the CF gene, and with mutations in other genes, such as SPINK1, CPA1, CASR, CTRC has not been well quantified.

The natural history of idiopathic pancreatitis differs based on the age at disease onset - this distinction has been well described for $\mathrm{CP}^{46}$, but not for RAP. Patients with early-onset idiopathic $\mathrm{CP}$ have disease course similar to patients with genetic susceptibility factors. In observational studies, between $20-50 \%$ of patients with idiopathic RAP progress to CP. ${ }^{78,87,90}$ Endoscopic therapy in these patients does not appear to alter the risk of progression to $\mathrm{CP}^{78,87}$

A recent retrospective study in a cohort of patients with HTG and pancreatitis reported the prevalence of RAP and CP to be 53\% and 17\%; and the risk of progression from RAP to CP to be $33 \% .{ }^{91}$ The risk of recurrences is directly linked to serum TG control, i.e. tight control is associated with reduced recurrences. ${ }^{92}$ Therefore, counseling for diet and lifestyle modification, diabetes control, and medical therapy could prevent disease progression. ${ }^{93}$

Compared to RAP, the natural history in patients with established $\mathrm{CP}$ has been well defined. Abdominal pain occurs in approximately $90 \%$ of patients at some time during the disease course. In a large US cohort of CP patients, 67\% reported severe pain, 53\% constant pain, and $16 \%$ no pain in the year preceding study enrollment. ${ }^{22}$ Exocrine insufficiency and type- 3 diabetes can develop in up to $87 \%$ and $80 \%$ respectively during the disease course. ${ }^{94}$ Pancreatic calcifications and ductal dilation can be present in $\sim 60 \%$ of patients. ${ }^{14}$ The course 
of clinical, functional and morphologic features varies with disease etiology - alcoholic CP has a more aggressive course when compared with other etiologies. Almost all patients with alcoholic and early-onset idiopathic CP have pain, while approximately half of those with late-onset idiopathic etiology have a painless course. ${ }^{46,94}$ End-stage features develop after a median of 5-10, 10-20, 20-30, and 30-40 years from the onset of symptoms in alcoholic, late-onset idiopathic, early-onset idiopathic, and hereditary $\mathrm{CP}$, respectively. ${ }^{43}, 46,84,94$

\section{Survival}

Several population studies evaluating the long-term survival after diagnosis of established $\mathrm{CP}$ have demonstrated a 2 to 5 -fold greater risk of death when compared with the sex-and age-matched population controls. ${ }^{32,95,96}$ Long-term survival after a first episode of AP was evaluated in a Danish population study with a 30-year follow-up. ${ }^{97}$ This study demonstrated that mortality rate in patients who did or did not progress to CP was 6 and 1.6 times the expected rate in the background population, respectively. Unfortunately, comparisons were not reported between AP patients who had recurrent attacks during follow up and those who progressed to CP. There are no data on long-term survival in patients with RAP. In another Danish study, mortality rate in patients with probable $\mathrm{CP}$ was 2.1 to 2.7 -fold greater when compared with the background population. ${ }^{95}$ Since probable $\mathrm{CP}$ is an intermediary stage for $\mathrm{CP}$, and a subset of these patients have RAP, these data suggest that mortality rate for RAP may be greater than expected, but lower when compared with $\mathrm{CP}$ patients.

The causes of death during long-term follow-up of patients with RAP have not been studied. In $\mathrm{CP}$, the most common causes of death include cancer (22-23\%), cardiovascular disease $(12-21 \%)$, and diseases of the alimentary tract (15-23\%). ${ }^{32,96,98}$ Many of these are linked to lifestyle factors and comorbidities in CP patients. ${ }^{96}$ When compared with general population, $\mathrm{CP}$ patients have a 13 -folds greater lifetime risk of pancreatic cancer, and also an increased risk of other malignancies (e.g. liver cancer, small intestinal cancer, lung cancer) and chronic conditions (e.g. chronic kidney disease, chronic pulmonary disease, cerebrovascular disease). ${ }^{96,99}$

\section{Quality of life (QOL)}

The effect of $\mathrm{CP}$ on QOL has been evaluated using different validated generic instruments (SF-36, SF-12, and EORTC QL-C30/QLQ-PAN26). A disease specific QOL instrument for $\mathrm{CP}$ has been developed and validated (PANQOLI), but has not been widely used yet. ${ }^{100}$ This 18 item-scale evaluates physical function, role function, emotional function, and self-worth (e.g. economic health, body image, stigma, and overall health). No validated disease specific instruments are available for RAP.

$\mathrm{CP}$ has a significant impact on QOL. In a study from the NAPS2 cohort, $\mathrm{CP}$ had an independent effect on both physical QOL and mental QOL when compared with controls with no pancreatic disease. ${ }^{101}$ In CP patients, pancreatic pain, especially constant, seems to be the predominant factor causing this impairment. ${ }^{102,103}$ Poor QOL may be a contributing factor for the high rates of unemployment, work absenteeism, and low annual personal income seen in these patients. ${ }^{104}$ There are no data on the effect of RAP on QOL. 


\section{Conclusions and future directions}

Studies in the past few years have convincingly demonstrated that AP, RAP and CP represent a disease continuum. RAP represents a high-risk group, comprised of individuals at varying risk of progression. Although many clinical factors have been identified, accurately predicting the disease course in individual patients remains difficult. Future studies should focus on providing more precise estimates of the risk of disease transition in a cohort of patients, quantification of clinical events during the natural course of disease, and discovery of biomarkers associated with different stages of disease. Availability of clinically-relevant endpoints and linked biomarkers will allow accurate prediction of disease course over an intermediate or long term based on characteristics of an individual patient. These endpoints will also provide objective measures for use in clinical trials of interventions that aim to alter the natural course of disease.

\section{Acknowledgments}

Dr. Yadav is supported in part by NIH (UO1 - DK108306).

\section{References}

1. Singer, MV., Gyr, K., Sarles, H. Revised classification of pancreatitis. Gastroenterology; Report of the Second International Symposium on the Classification of Pancreatitis; Marseille, France. March 28-30, 1984; 1985. p. 683-5.

2. Sarner M, Cotton PB. Classification of pancreatitis. Gut. 1984; 25:756-9. [PubMed: 6735257]

3. Pitchumoni CS, Glasser M, Saran RM, et al. Pancreatic fibrosis in chronic alcoholics and nonalcoholics without clinical pancreatitis. Am J Gastroenterol. 1984; 79:382-8. [PubMed: 6720660]

4. Comfort MW, Gambill EE, Baggenstoss AH. Chronic relapsing pancreatitis; a study of 29 cases without associated disease of the biliary or gastrointestinal tract. Gastroenterology. 1946; 6:376408. [PubMed: 20985712]

5. Kloppel G, Maillet B. Pseudocysts in chronic pancreatitis: a morphological analysis of 57 resection specimens and 9 autopsy pancreata. Pancreas. 1991; 6:266-74. [PubMed: 1862065]

6. Kloppel G, Maillet B. The morphological basis for the evolution of acute pancreatitis into chronic pancreatitis. Virchows Arch A Pathol Anat Histopathol. 1992; 420:1-4. [PubMed: 1539444]

7. Ammann RW, Muellhaupt B. Progression of alcoholic acute to chronic pancreatitis. Gut. 1994; 35:552-6. [PubMed: 8174996]

8. Ammann RW, Heitz PU, Kloppel G. Course of alcoholic chronic pancreatitis: a prospective clinicomorphological long-term study. Gastroenterology. 1996; 111:224-31. [PubMed: 8698203]

9. Whitcomb DC. Hereditary pancreatitis: new insights into acute and chronic pancreatitis. Gut. 1999; 45:317-22. [PubMed: 10446089]

10. Sankaran SJ, Xiao AY, Wu LM, et al. Frequency of progression from acute to chronic pancreatitis and risk factors: a meta-analysis. Gastroenterology. 2015; 149:1490-1500. e1. [PubMed: 26299411]

11. Ahmed Ali U, Issa Y, Hagenaars JC, et al. Risk of Recurrent Pancreatitis and Progression to Chronic Pancreatitis After a First Episode of Acute Pancreatitis. Clin Gastroenterol Hepatol. 2016; 14:738-46. [PubMed: 26772149]

12. Doubilet H, Mulholland JH. Recurrent acute pancreatitis; observations on etiology and surgical treatment. Ann Surg. 1948; 128:609-38.

13. Sarles H. Proposal adopted unanimously by the participants of the Symposium, Marseilles 1963. Bibl Gastroenterol. 1965; 7:7-8. 
14. Wilcox CM, Sandhu BS, Singh V, et al. Racial Differences in the Clinical Profile, Causes, and Outcome of Chronic Pancreatitis. Am J Gastroenterol. 2016; 111:1488-1496. [PubMed: 27527745]

15. Sarles H, Adler G, Dani R, et al. The pancreatitis classification of Marseilles-Rome 1988. Scand J Gastroenterol. 1989; 24:641-2. [PubMed: 2814334]

16. Homma T, Harada H, Koizumi M. Diagnostic criteria for chronic pancreatitis by the Japan Pancreas Society. Pancreas. 1997; 15:14-5. [PubMed: 9211487]

17. Ammann RW. A clinically based classification system for alcoholic chronic pancreatitis: summary of an international workshop on chronic pancreatitis. Pancreas. 1997; 14:215-21. [PubMed: 9094150]

18. Etemad B, Whitcomb DC. Chronic pancreatitis: diagnosis, classification, and new genetic developments. Gastroenterology. 2001; 120:682-707. [PubMed: 11179244]

19. Conwell DL, Lee LS, Yadav D, et al. American Pancreatic Association Practice Guidelines in Chronic Pancreatitis: evidence-based report on diagnostic guidelines. Pancreas. 2014; 43:1143-62. [PubMed: 25333398]

20. Hoffmeister A, Mayerle J, Beglinger C, et al. English language version of the S3-consensus guidelines on chronic pancreatitis: Definition, aetiology, diagnostic examinations, medical, endoscopic and surgical management of chronic pancreatitis. Z Gastroenterol. 2015; 53:1447-95. [PubMed: 26666283]

21. Shimosegawa T, Kataoka K, Kamisawa T, et al. The revised Japanese clinical diagnostic criteria for chronic pancreatitis. J Gastroenterol. 2010; 45:584-91. [PubMed: 20422433]

22. Wilcox CM, Yadav D, Ye T, et al. Chronic pancreatitis pain pattern and severity are independent of abdominal imaging findings. Clin Gastroenterol Hepatol. 2015; 13:552-60. quiz e28-9. [PubMed: 25424572]

23. Whitcomb DC, Frulloni L, Garg P, et al. Chronic pancreatitis: An international draft consensus proposal for a new mechanistic definition. Pancreatology. 2016; 16:218-24. [PubMed: 26924663]

24. Yadav D, Lowenfels AB. Trends in the epidemiology of the first attack of acute pancreatitis: a systematic review. Pancreas. 2006; 33:323-30. [PubMed: 17079934]

25. Frey CF, Zhou H, Harvey DJ, et al. The incidence and case-fatality rates of acute biliary, alcoholic, and idiopathic pancreatitis in California, 1994-2001. Pancreas. 2006; 33:336-44. [PubMed: 17079936]

26. Sandzen B, Rosenmuller M, Haapamaki MM, et al. First attack of acute pancreatitis in Sweden 1988 - 2003: incidence, aetiological classification, procedures and mortality - a register study. BMC Gastroenterol. 2009; 9:18. [PubMed: 19265519]

27. Omdal T, Dale J, Lie SA, et al. Time trends in incidence, etiology, and case fatality rate of the first attack of acute pancreatitis. Scand J Gastroenterol. 2011; 46:1389-98. [PubMed: 21830851]

28. Satoh K, Shimosegawa T, Masamune A, et al. Nationwide epidemiological survey of acute pancreatitis in Japan. Pancreas. 2011; 40:503-7. [PubMed: 21499203]

29. Shen HN, Lu CL, Li CY. Epidemiology of first-attack acute pancreatitis in Taiwan from 2000 through 2009: a nationwide population-based study. Pancreas. 2012; 41:696-702. [PubMed: 22699142]

30. Hirota M, Shimosegawa T, Masamune A, et al. The sixth nationwide epidemiological survey of chronic pancreatitis in Japan. Pancreatology. 2012; 12:79-84. [PubMed: 22487515]

31. Hirota M, Shimosegawa T, Masamune A, et al. The seventh nationwide epidemiological survey for chronic pancreatitis in Japan: clinical significance of smoking habit in Japanese patients. Pancreatology. 2014; 14:490-6. [PubMed: 25224249]

32. Yadav D, Timmons L, Benson JT, et al. Incidence, prevalence, and survival of chronic pancreatitis: a population-based study. Am J Gastroenterol. 2011; 106:2192-9. [PubMed: 21946280]

33. Levy P, Barthet M, Mollard BR, et al. Estimation of the prevalence and incidence of chronic pancreatitis and its complications. Gastroenterol Clin Biol. 2006; 30:838-44. [PubMed: 16885867]

34. Dominguez-Munoz JE, Lucendo A, Carballo LF, et al. A Spanish multicenter study to estimate the prevalence and incidence of chronic pancreatitis and its complications. Rev Esp Enferm Dig. 2014; 106:239-45. [PubMed: 25075654]

Dig Dis Sci. Author manuscript; available in PMC 2018 July 01. 
35. Wang LW, Li ZS, Li SD, et al. Prevalence and clinical features of chronic pancreatitis in China: a retrospective multicenter analysis over 10 years. Pancreas. 2009; 38:248-54. [PubMed: 19034057]

36. Gullo L, Migliori M, Pezzilli R, et al. An update on recurrent acute pancreatitis: data from five European countries. Am J Gastroenterol. 2002; 97:1959-62. [PubMed: 12190160]

37. Sajith KG, Chacko A, Dutta AK. Recurrent acute pancreatitis: clinical profile and an approach to diagnosis. Dig Dis Sci. 2010; 55:3610-6. [PubMed: 20232145]

38. Gao YJ, Li YQ, Wang Q, et al. Analysis of the clinical features of recurrent acute pancreatitis in China. J Gastroenterol. 2006; 41:681-5. [PubMed: 16933006]

39. Andersson R, Andersson B, Haraldsen P, et al. Incidence, management and recurrence rate of acute pancreatitis. Scand J Gastroenterol. 2004; 39:891-4. [PubMed: 15513389]

40. Cavallini G, Frulloni L, Pederzoli P, et al. Long-term follow-up of patients with chronic pancreatitis in Italy. Scand J Gastroenterol. 1998; 33:880-9. [PubMed: 9754738]

41. Frulloni L, Gabbrielli A, Pezzilli R, et al. Chronic pancreatitis: report from a multicenter Italian survey (PanCroInfAISP) on 893 patients. Dig Liver Dis. 2009; 41:311-7. [PubMed: 19097829]

42. Yadav D, O’Connell M, Papachristou GI. Natural history following the first attack of acute pancreatitis. Am J Gastroenterol. 2012; 107:1096-103. [PubMed: 22613906]

43. Howes N, Lerch MM, Greenhalf W, et al. Clinical and genetic characteristics of hereditary pancreatitis in Europe. Clin Gastroenterol Hepatol. 2004; 2:252-61. [PubMed: 15017610]

44. Rebours V, Boutron-Ruault MC, Schnee M, et al. The natural history of hereditary pancreatitis: a national series. Gut. 2009; 58:97-103. [PubMed: 18755888]

45. Lankisch PG, Assmus C, Maisonneuve P, et al. Epidemiology of pancreatic diseases in Luneburg County. A study in a defined german population. Pancreatology. 2002; 2:469-77. [PubMed: 12378115]

46. Layer P, Yamamoto H, Kalthoff L, et al. The different courses of early- and late-onset idiopathic and alcoholic chronic pancreatitis. Gastroenterology. 1994; 107:1481-7. [PubMed: 7926511]

47. Fagenholz PJ, Castillo CF, Harris NS, et al. Increasing United States hospital admissions for acute pancreatitis, 1988-2003. Ann Epidemiol. 2007; 17:491-7. [PubMed: 17448682]

48. van Geenen EJ, van der Peet DL, Mulder CJ, et al. Recurrent acute biliary pancreatitis: the protective role of cholecystectomy and endoscopic sphincterotomy. Surg Endosc. 2009; 23:950-6. [PubMed: 19266236]

49. da Costa DW, Bouwense SA, Schepers NJ, et al. Same-admission versus interval cholecystectomy for mild gallstone pancreatitis (PONCHO): a multicentre randomised controlled trial. Lancet. 2015; 386:1261-8. [PubMed: 26460661]

50. Takeyama Y. Long-term prognosis of acute pancreatitis in Japan. Clin Gastroenterol Hepatol. 2009; 7:S15-7. [PubMed: 19896091]

51. Irving HM, Samokhvalov AV, Rehm J. Alcohol as a risk factor for pancreatitis. A systematic review and meta-analysis. JOP. 2009; 10:387-92. [PubMed: 19581740]

52. Samokhvalov AV, Rehm J, Roerecke M. Alcohol Consumption as a Risk Factor for Acute and Chronic Pancreatitis: A Systematic Review and a Series of Meta-analyses. EBioMedicine. 2015; 2:1996-2002. [PubMed: 26844279]

53. Kume K, Masamune A, Ariga H, et al. Alcohol Consumption and the Risk for Developing Pancreatitis: A Case-Control Study in Japan. Pancreas. 2015; 44:53-8. [PubMed: 25386904]

54. Katz M, Carangelo R, Miller LJ, et al. Effect of ethanol on cholecystokinin-stimulated zymogen conversion in pancreatic acinar cells. Am J Physiol. 1996; 270:G171-5. [PubMed: 8772515]

55. Pandol SJ, Periskic S, Gukovsky I, et al. Ethanol diet increases the sensitivity of rats to pancreatitis induced by cholecystokinin octapeptide. Gastroenterology. 1999; 117:706-16. [PubMed: 10464148]

56. Greer JB, Thrower E, Yadav D. Epidemiologic and Mechanistic Associations Between Smoking and Pancreatitis. Curr Treat Options Gastroenterol. 2015; 13:332-46. [PubMed: 26109145]

57. Andriulli A, Botteri E, Almasio PL, et al. Smoking as a cofactor for causation of chronic pancreatitis: a meta-analysis. Pancreas. 2010; 39:1205-10. [PubMed: 20622705]

Dig Dis Sci. Author manuscript; available in PMC 2018 July 01. 
58. Whitcomb DC, LaRusch J, Krasinskas AM, et al. Common genetic variants in the CLDN2 and PRSS1-PRSS2 loci alter risk for alcohol-related and sporadic pancreatitis. Nat Genet. 2012; 44:1349-54. [PubMed: 23143602]

59. Derikx MH, Kovacs P, Scholz M, et al. Polymorphisms at PRSS1-PRSS2 and CLDN2-MORC4 loci associate with alcoholic and non-alcoholic chronic pancreatitis in a European replication study. Gut. 2015; 64:1426-33. [PubMed: 25253127]

60. Zhong Y, Cao J, Zou R, et al. Genetic polymorphisms in alcohol dehydrogenase, aldehyde dehydrogenase and alcoholic chronic pancreatitis susceptibility: a meta-analysis. Gastroenterol Hepatol. 2015; 38:417-25. [PubMed: 25541509]

61. Whitcomb DC, Gorry MC, Preston RA, et al. Hereditary pancreatitis is caused by a mutation in the cationic trypsinogen gene. Nat Genet. 1996; 14:141-5. [PubMed: 8841182]

62. Witt H, Sahin-Toth M, Landt O, et al. A degradation-sensitive anionic trypsinogen (PRSS2) variant protects against chronic pancreatitis. Nat Genet. 2006; 38:668-73. [PubMed: 16699518]

63. Aoun E, Muddana V, Papachristou GI, et al. SPINK1 N34S is strongly associated with recurrent acute pancreatitis but is not a risk factor for the first or sentinel acute pancreatitis event. Am $\mathrm{J}$ Gastroenterol. 2010; 105:446-51. [PubMed: 19888199]

64. Midha S, Khajuria R, Shastri S, et al. Idiopathic chronic pancreatitis in India: phenotypic characterisation and strong genetic susceptibility due to SPINK1 and CFTR gene mutations. Gut. 2010; 59:800-7. [PubMed: 20551465]

65. Aoun E, Chang CC, Greer JB, et al. Pathways to injury in chronic pancreatitis: decoding the role of the high-risk SPINK1 N34S haplotype using meta-analysis. PLoS One. 2008; 3:e2003. [PubMed: 18414673]

66. Chang YT, Wei SC, LPC, et al. Association and differential role of PRSS1 and SPINK1 mutation in early-onset and late-onset idiopathic chronic pancreatitis in Chinese subjects. Gut. 2009; 58:885. [PubMed: 19433603]

67. Cohn JA, Friedman KJ, Noone PG, et al. Relation between mutations of the cystic fibrosis gene and idiopathic pancreatitis. N Engl J Med. 1998; 339:653-8. [PubMed: 9725922]

68. Ooi CY, Dorfman R, Cipolli M, et al. Type of CFTR mutation determines risk of pancreatitis in patients with cystic fibrosis. Gastroenterology. 2011; 140:153-61. [PubMed: 20923678]

69. LaRusch J, Jung J, General IJ, et al. Mechanisms of CFTR functional variants that impair regulated bicarbonate permeation and increase risk for pancreatitis but not for cystic fibrosis. PLoS Genet. 2014; 10:e1004376. [PubMed: 25033378]

70. Whitcomb DC. Genetic risk factors for pancreatic disorders. Gastroenterology. 2013; 144:1292302. [PubMed: 23622139]

71. Scherer J, Singh VP, Pitchumoni CS, et al. Issues in hypertriglyceridemic pancreatitis: an update. J Clin Gastroenterol. 2014; 48:195-203. [PubMed: 24172179]

72. Pedersen SB, Langsted A, Nordestgaard BG. Nonfasting Mild-to-Moderate Hypertriglyceridemia and Risk of Acute Pancreatitis. JAMA Intern Med. 2016; 176:1834-1842. [PubMed: 27820614]

73. Bai HX, Giefer M, Patel M, et al. The association of primary hyperparathyroidism with pancreatitis. J Clin Gastroenterol. 2012; 46:656-61. [PubMed: 22874807]

74. Bulow R, Simon P, Thiel R, et al. Anatomic variants of the pancreatic duct and their clinical relevance: an MR-guided study in the general population. Eur Radiol. 2014; 24:3142-9. [PubMed: 25120204]

75. Bertin C, Pelletier AL, Vullierme MP, et al. Pancreas divisum is not a cause of pancreatitis by itself but acts as a partner of genetic mutations. Am J Gastroenterol. 2012; 107:311-7. [PubMed: 22158025]

76. Cotton PB, Durkalski V, Romagnuolo J, et al. Effect of endoscopic sphincterotomy for suspected sphincter of Oddi dysfunction on pain-related disability following cholecystectomy: the EPISOD randomized clinical trial. JAMA. 2014; 311:2101-9. [PubMed: 24867013]

77. Elta GH. Sphincter of Oddi dysfunction and bile duct microlithiasis in acute idiopathic pancreatitis. World J Gastroenterol. 2008; 14:1023-6. [PubMed: 18286682]

78. Cote GA, Imperiale TF, Schmidt SE, et al. Similar efficacies of biliary, with or without pancreatic, sphincterotomy in treatment of idiopathic recurrent acute pancreatitis. Gastroenterology. 2012; 143:1502-1509. e1. [PubMed: 22982183] 
79. Spanier BW, Tuynman HA, van der Hulst RW, et al. Acute pancreatitis and concomitant use of pancreatitis-associated drugs. Am J Gastroenterol. 2011; 106:2183-8. [PubMed: 21912439]

80. Sadr-Azodi O, Sanders DS, Murray JA, et al. Patients with celiac disease have an increased risk for pancreatitis. Clin Gastroenterol Hepatol. 2012; 10:1136-1142. e3. [PubMed: 22801059]

81. Patel RS, Johlin FC Jr, Murray JA. Celiac disease and recurrent pancreatitis. Gastrointest Endosc. 1999; 50:823-7. [PubMed: 10570344]

82. Sah RP, Pannala R, Chari ST, et al. Prevalence, diagnosis, and profile of autoimmune pancreatitis presenting with features of acute or chronic pancreatitis. Clin Gastroenterol Hepatol. 2010; 8:91-6. [PubMed: 19800984]

83. Hart PA, Kamisawa T, Brugge WR, et al. Long-term outcomes of autoimmune pancreatitis: a multicentre, international analysis. Gut. 2013; 62:1771-6. [PubMed: 23232048]

84. Ammann RW, Muellhaupt B, Meyenberger C, et al. Alcoholic nonprogressive chronic pancreatitis: prospective long-term study of a large cohort with alcoholic acute pancreatitis (1976-1992). Pancreas. 1994; 9:365-73. [PubMed: 8022760]

85. Bertilsson S, Sward P, Kalaitzakis E. Factors That Affect Disease Progression After First Attack of Acute Pancreatitis. Clin Gastroenterol Hepatol. 2015; 13:1662-9. e3. [PubMed: 25911118]

86. Lankisch PG, Breuer N, Bruns A, et al. Natural history of acute pancreatitis: a long-term population-based study. Am J Gastroenterol. 2009; 104:2797-805. quiz 2806. [PubMed: 19603011]

87. Das R, Clarke B, Tang G, et al. Endoscopic sphincterotomy (ES) may not alter the natural history of idiopathic recurrent acute pancreatitis (IRAP). Pancreatology. 2016; 16:770-7. [PubMed: 27450967]

88. Nordback I, Pelli H, Lappalainen-Lehto R, et al. The recurrence of acute alcohol-associated pancreatitis can be reduced: a randomized controlled trial. Gastroenterology. 2009; 136:848-55. [PubMed: 19162029]

89. Pelli H, Lappalainen-Lehto R, Piironen A, et al. Risk factors for recurrent acute alcohol-associated pancreatitis: a prospective analysis. Scand J Gastroenterol. 2008; 43:614-21. [PubMed: 18415757]

90. Garg PK, Tandon RK, Madan K. Is biliary microlithiasis a significant cause of idiopathic recurrent acute pancreatitis? A long-term follow-up study. Clin Gastroenterol Hepatol. 2007; 5:75-9. [PubMed: 16931169]

91. Vipperla K, Somerville C, Furlan A, et al. Clinical Profile and Natural Course in a Large Cohort of Patients With Hypertriglyceridemia and Pancreatitis. J Clin Gastroenterol. 2017; 51:77-85. [PubMed: 27322530]

92. Christian JB, Arondekar B, Buysman EK, et al. Determining triglyceride reductions needed for clinical impact in severe hypertriglyceridemia. Am J Med. 2014; 127:36-44. e1. [PubMed: 24384100]

93. Berglund L, Brunzell JD, Goldberg AC, et al. Treatment options for hypertriglyceridemia: from risk reduction to pancreatitis. Best Pract Res Clin Endocrinol Metab. 2014; 28:423-37. [PubMed: 24840268]

94. Ammann RW, Akovbiantz A, Largiader F, et al. Course and outcome of chronic pancreatitis. Longitudinal study of a mixed medical-surgical series of 245 patients. Gastroenterology. 1984; 86:820-8. [PubMed: 6706066]

95. Nojgaard C, Bendtsen F, Becker U, et al. Danish patients with chronic pancreatitis have a four-fold higher mortality rate than the Danish population. Clin Gastroenterol Hepatol. 2010; 8:384-90. [PubMed: 20036762]

96. Bang UC, Benfield T, Hyldstrup L, et al. Mortality, cancer, and comorbidities associated with chronic pancreatitis: a Danish nationwide matched-cohort study. Gastroenterology. 2014; 146:989-94. [PubMed: 24389306]

97. Nojgaard C, Becker U, Matzen P, et al. Progression from acute to chronic pancreatitis: prognostic factors, mortality, and natural course. Pancreas. 2011; 40:1195-200. [PubMed: 21926938]

98. Lowenfels AB, Maisonneuve P, Cavallini G, et al. Prognosis of chronic pancreatitis: an international multicenter study. International Pancreatitis Study Group. Am J Gastroenterol. 1994; 89:1467-71. [PubMed: 8079921] 
99. Raimondi S, Lowenfels AB, Morselli-Labate AM, et al. Pancreatic cancer in chronic pancreatitis; aetiology, incidence, and early detection. Best Pract Res Clin Gastroenterol. 2010; 24:349-58. [PubMed: 20510834]

100. Wassef W, DeWitt J, McGreevy K, et al. Pancreatitis Quality of Life Instrument: A Psychometric Evaluation. Am J Gastroenterol. 2016; 111:1177-86. [PubMed: 27296943]

101. Amann ST, Yadav D, Barmada MM, et al. Physical and mental quality of life in chronic pancreatitis: a case-control study from the North American Pancreatitis Study 2 cohort. Pancreas. 2013; 42:293-300. [PubMed: 23357924]

102. Mullady DK, Yadav D, Amann ST, et al. Type of pain, pain-associated complications, quality of life, disability and resource utilisation in chronic pancreatitis: a prospective cohort study. Gut. 2011; 60:77-84. [PubMed: 21148579]

103. Pezzilli R, Morselli-Labate AM, Frulloni L, et al. The quality of life in patients with chronic pancreatitis evaluated using the SF-12 questionnaire: a comparative study with the SF-36 questionnaire. Dig Liver Dis. 2006; 38:109-15. [PubMed: 16243011]

104. Gardner TB, Kennedy AT, Gelrud A, et al. Chronic pancreatitis and its effect on employment and health care experience: results of a prospective American multicenter study. Pancreas. 2010; 39:498-501. [PubMed: 20118821] 


\section{Key findings/future unmet needs/implications}

- $\quad$ Acute pancreatitis (AP), recurrent acute pancreatitis (RAP) and chronic pancreatitis $(\mathrm{CP})$ represent a disease continuum.

- Disease progression is dependent on clinical factors, such as etiology, ongoing risk factors, and local complications.

- Future studies should provide more precise estimates of the risk of disease transition in a cohort of RAP and CP patients, and quantify clinically relevant outcomes during disease course. This approach combined with collection of biological samples at different stages of diseases will allow discovery of biomarkers of disease progression.

- Information on clinically relevant endpoints and biomarkers of disease will provide objective measures to use for interventions that aim to alter the natural course of disease. 
Table 1

Causes of recurrent acute and chronic pancreatitis

\begin{tabular}{|c|c|c|}
\hline \multirow[t]{2}{*}{ Cause $(\%)$} & \multicolumn{2}{|c|}{ Approximate frequency } \\
\hline & RAP & $\mathbf{C P}$ \\
\hline Gallstones & $10-30$ & Rare \\
\hline Alcohol & $25-50$ & $40-70$ \\
\hline Idiopathic & $10-30$ & $20-30$ \\
\hline Genetic- CFTR, SPINK1, PRSS1, CTRC, CPA & $5-10$ & $10-15$ \\
\hline Hypertriglyceridemia & $3-5$ & $1-2$ \\
\hline Autoimmune Pancreatitis & 2 & 2 \\
\hline Celiac disease & 1 & 1 \\
\hline Other autoimmune diseases & 1 & 1 \\
\hline Post-necrotic & Unknown & 3 \\
\hline Obstructive causes (e.g. stricture, tumor) & $<5 \%$ & $<5 \%$ \\
\hline Pancreas divisum & Controversial & Controversial \\
\hline Sphincter of Oddi dysfunction & Controversial & Controversial \\
\hline Hypercalcemia & Rare & Rare \\
\hline Drugs & Rare & 0 \\
\hline
\end{tabular}

